\title{
Aquisição de alimentos da agricultura familiar para a alimentação escolar segundo regiões brasileiras: uma revisão
}

\author{
Acquisition of family agriculture foods for school food according to brazilian regions: a review \\ Adquisición de alimentos de agricultura familiar para el alimentación escolar según regiones \\ brasileñas: revisión
}

Recebido: 26/02/2021 | Revisado: 04/03/2021 | Aceito: 09/03/2021 | Publicado: 17/03/2021

\author{
Cassia Bonfim de Oliveira \\ ORCID: https://orcid.org/0000-0003-0819-7728 \\ Universidade Federal de Sergipe, Brasil \\ E-mail: cassia.nutri6@gmail.com \\ Andhressa Araújo Fagundes \\ ORCID: https://orcid.org/0000-0003-4085-3270 \\ Universidade Federal de Sergipe, Brasil \\ E-mail: andhressa@academico.ufs.br \\ Renata Lopes de Siqueira \\ ORCID: https://orcid.org/0000-0002-4776-146X \\ Universidade Federal de Sergipe, Brasil \\ E-mail: renata.educacao@gmail.com
}

\begin{abstract}
Resumo
Introdução: A Lei no 11.947/2009 institui que, no mínimo, 30\% do total de recursos financeiros repassados no âmbito do Programa Nacional de Alimentação Escolar (PNAE), deverá ser utilizado na aquisição de alimentos da agricultura familiar e empreendimentos familiares rurais. Objetivo: O presente estudo traça um panorama da aquisição de gêneros alimentícios da agricultura familiar para o PNAE, ao analisar o cumprimento do percentual mínimo exigido por Lei nas cinco regiões do Brasil. Metodologia: Trata-se de uma revisão da literatura do período de 2009 a 2019. Foram selecionados trinta artigos nas bases de dados Scielo, Spell e Pubmed. Resultados: Houve aquisição de alimentos para o PNAE em todas as regiões brasileiras. A região Sul apresentou maior prevalência de Entidades Executoras (EEx) que aplicaram recursos abaixo do percentual de 30\% em 2011, 2013 e 2014. Paradoxalmente, esta região apresentou maior prevalência de EEx que atingiram porcentagem igual ou maior que $30 \%$ de aplicação dos recursos do PNAE na agricultura familiar no mesmo período. Conclusão: Os resultados demonstram que os municípios e estados apresentam dificuldades distintas em cumprir o percentual exigido por Lei, e estas estão associadas às desigualdades sociais, econômicas, culturais e ambientais manifestas em cada região brasileira.
\end{abstract}

Palavras-chave: Alimentação escolar; Agricultura familiar; Programas e políticas de nutrição e alimentação; Saúde pública; Brasil.

\begin{abstract}
Introduction: Law 11.947/2009 establishes that, at least, 30\% of the total financial resources transferred under the National School Feeding Program (PNAE), should be used to purchase food from family farming and rural family enterprises. Objective: The present study provides an overview of the acquisition of food from family agriculture for the PNAE, by analyzing compliance with the minimum percentage required by law in the five regions of Brazil. Methodology: It is a literature review for the period from 2009 to 2019. For this purpose, thirty articles were selected from the Scielo, Spell and Pubmed databases. Results: There was acquisition of food for PNAE in all Brazilian regions. The South region has a higher prevalence of Executing Entities that applied resources below the stipulated percentage of 30\% in 2011, 2013 and 2014. Paradoxically, this region has a higher prevalence of Executing Entities that have invested more than $30 \%$ of PNAE resources from family agriculture in the same period. Conclusion: The results show that municipalities and states have distinct difficulties in meeting the percentage required by law, and these are associated with the social, economic, cultural and environmental inequalities evident in each Brazilian region.
\end{abstract}

Keywords: School feeding; Family farming; Nutrition and food programs and policies; Public health; Brazil.

\section{Resumen}

Introducción: La Ley 11.947/2009 establece que, al menos, el 30\% del total de los recursos financieros transferidos bajo el Programa Nacional de Alimentación Escolar (PNAE), debe destinarse a la compra de alimentos a la agricultura familiar y empresas familiares rurales. Objetivo: El presente estudio ofrece una visión general de la adquisición de alimentos de la agricultura familiar para el PNAE, analizando el cumplimiento del porcentaje mínimo 
exigido por la ley en las cinco regiones de Brasil. Metodología: Se trata de una revisión de la literatura de 2009 a 2019. Se seleccionaron 30 artículos de las bases de datos Scielo, Spell y Pubmed. Resultados: Se compraron alimentos para el PNAE en todas las regiones brasileñas. La región Sur tuvo una mayor prevalencia de Entidades Ejecutoras (EEx) que invirtieron recursos por debajo del porcentaje del 30\% en 2011, 2013 y 2014. Paradójicamente, esta región mostró una mayor prevalencia de EEx que alcanzó un porcentaje igual o superior al 30\% de la aplicación de recursos del PNAE en la agricultura familiar en el mismo período. Conclusión: Los resultados muestran que los municipios y los estados tienen diferentes dificultades para cumplir con el porcentaje exigido por la Ley, y estos se asocian con las desigualdades sociales, económicas, culturales y ambientales que se manifiestan en cada región brasileña.

Palabras clave: Alimentación escolar; Agricultura familiar; Programas y políticas de nutrición y alimentación; Salud pública; Brasil.

\section{Introdução}

O Programa Nacional de Alimentação Escolar (PNAE) implementado em 1955, é o mais antigo programa de alimentação e nutrição em vigor no Brasil (Malaguti, 2015). Até 1994, o processo de aquisição de gêneros alimentícios para o PNAE era centralizado, efetuado por licitação pública. Esses produtos adquiridos eram distribuídos para todo o território nacional, não considerando os aspectos culturais locais (Pedraza, Melo, Silva \& Araújo, 2018; Peixinho, 2013; Triches, Barbosa \& Silvestri, 2016).

Ao longo do tempo, o programa sofreu mudanças no processo de aquisição. Em 2009, já integrando a Política Nacional de Segurança Alimentar e Nutricional (PNSAN), que visa a realização do Direito Humano à Alimentação Adequada (DHAA), foi promulgado um novo marco legal de regulação do PNAE, a Lei n 11.947/2009 (Lei n 11.947, 2009).

Objetivando a melhoria da qualidade nutricional da alimentação escolar e o fortalecimento da produção local (Baccarin, Triches, Teo \& Silva, 2017; Resolução/CD/FNDE nº 26, 2013), a referida Lei instituiu a obrigatoriedade de utilização de, no mínimo, 30\% dos recursos financeiros provenientes do Fundo Nacional de Desenvolvimento da Educação (FNDE) para a compra direta de alimentos da Agricultura Familiar (AF) e suas organizações. A Lei também prevê que as compras da AF ocorram por meio de Chamada Pública, com dispensa de processo licitatório (Lei n 11.947, 2009; Resolução/CD/FNDE nº 38, 2009; Resolução/CD/FNDE n 26, 2013; Resolução n. ${ }^{\circ}$ 4, 2015; Resolução nº 6, 2020).

Entretanto, a hipótese é de que muitos estados e municípios não conseguem cumprir o percentual de aplicação dos recursos do FNDE exigido, pois enfrentam dificuldades na aquisição dos gêneros alimentícios provenientes da AF (Araújo, Brito, Rodrigues, Mascarenhas \& Moreira-Araújo, 2019; Messias, 2018; Silva \& Souza, 2013). Tal hipótese fundamentou-se no reconhecimento das desigualdades socioeconômicas, culturais e ambientais vivenciadas pelos 27 estados e 5.570 municípios responsáveis pela execução do PNAE em todo o território nacional. Estas discrepâncias devem ser cientificamente evidenciadas para que possam ser enfrentadas pelos atores sociais envolvidos no processo de gestão do PNAE.

Destarte, o presente estudo tem como objetivo traçar um panorama da aquisição dos gêneros alimentícios da AF para o PNAE, analisando o cumprimento do percentual mínimo exigido em diferentes regiões do Brasil.

Estudos desta natureza são relevantes, pois mostram quais regiões cumprem os requisitos legais do PNAE e, consequentemente, atendem os princípios norteadores do programa, dados pouco evidenciados na literatura. Além disso, poderá demonstrar a necessidade de fortalecer e criar políticas que apoiem os agricultores familiares, assim como, valorizem a produção deste segmento.

Ademais, considerando a importância da AF para a efetividade do PNAE na promoção da alimentação saudável e no desenvolvimento rural e sustentabilidade da produção local, esse estudo poderá contribuir para o ajuste do processo de aquisição da AF e realização do DHAA dos agricultores familiares e escolares dos diferentes estados e municípios. 


\section{Metodologia}

Trata-se de uma revisão da literatura, de abordagem quantitativa descritiva, sobre os estudos relativos à compra de gêneros alimentícios da AF para o PNAE Nesse tipo de estudo, o conjunto de dados pode ser analisado através de critérios numéricos e analíticos aplicáveis ao objeto em estudo (Pereira et al., 2018).

Procedeu-se a seleção dos estudos nas bases de dados Scientific Electronic Library Online (SciELO), US National Library of Mediacine National Institutes of Health (Pubmed) e no repositório da Scientific Periodicals Electronic Library (Spell).

A busca, realizada entre abril e maio de 2020, adotou os seguintes descritores: "alimentação escolar" and "agricultura familiar", "alimentação escolar" and "orgânicos", "alimentação escolar" and "agroecológicos", "alimentação escolar" and "quilombolas", "alimentação escolar" and "indígenas", "alimentação escolar" and "assentados", "compras institucionais" and "agricultura familiar", e seus correspondentes em inglês e espanhol. Foi averiguada a duplicação dos trabalhos nas bases de dados, sendo cada artigo contabilizado somente uma vez.

Os critérios de inclusão foram os artigos ori-ginais relacionados à aquisição de gêneros alimentícios proveniente da AF para o PNAE, cujos dados das análises foram relativos ao período de gestão do PNAE entre os anos de 2009 a 2019. A escolha dos estudos neste período justifica-se pelo fato de que a Lei ${ }^{\circ} 11.947$, marco legal do PNAE, foi promulgada em 2009.

Excluiu-se artigos de revisão, resumos de congressos, monografias, dissertações, teses e os estudos sobre o PNAE que não se debruçaram sobre os aspectos relativos à aquisição de alimentos da $\mathrm{AF}$. Os manuscritos selecionados após esse processo foram submetidos à leitura e análise criteriosa do texto integral.

Como procedimento de análise dos resultados, inicialmente, efetuou-se a caracterização dos artigos considerando o ano de publicação, autores, procedimentos metodológicos, local e sujeitos da pesquisa. Na sequência, procedeu-se a análise descritiva das variáveis compatíveis com o objetivo do artigo, quais sejam: cumprimento da aplicação do percentual mínimo exigido dos recursos na aquisição de gêneros da $\mathrm{AF}$ (30\%) e a localização geográfica de abrangência do estudo.

Desta forma, avaliou-se a frequência dos estados e ou municípios que aplicaram percentual dos recursos financeiros menor que $30 \%$ e igual ou maior que $30 \%$ na aquisição de gêneros alimentícios da AF, assim como, a respectiva distribuição dos mesmos nas cinco regiões brasileiras (Centro-oeste, Nordeste, Norte, Sudeste e Sul).

A Figura 1 sistematiza o processo de busca eletrônica e a identificação dos artigos nas bases de dados. Foram identificados 608 estudos. Foram excluídos 128, por se tratar de dissertações, teses, artigos de revisão e comunicações breves. Em seguida, eliminou-se 9 artigos não disponíveis gratuitamente, bem como 53 que não correspondiam ao período estabelecido. Após a leitura dos títulos, foram eliminados 38 duplicados e 193 que, após a leitura dos resumos, não contemplavam a temática. Resultaram 187 artigos para leitura integral. Destes, foram excluídos 157 que não contemplaram os parâmetros de análise da presente pesquisa (percentual de aquisição da AF e localização geográfica dos municípios), o que resultou em um total de 30 artigos como material de pesquisa. 
Figura 1 - Fluxograma de busca eletrônica nas bases de dados científicas para seleção de artigos.

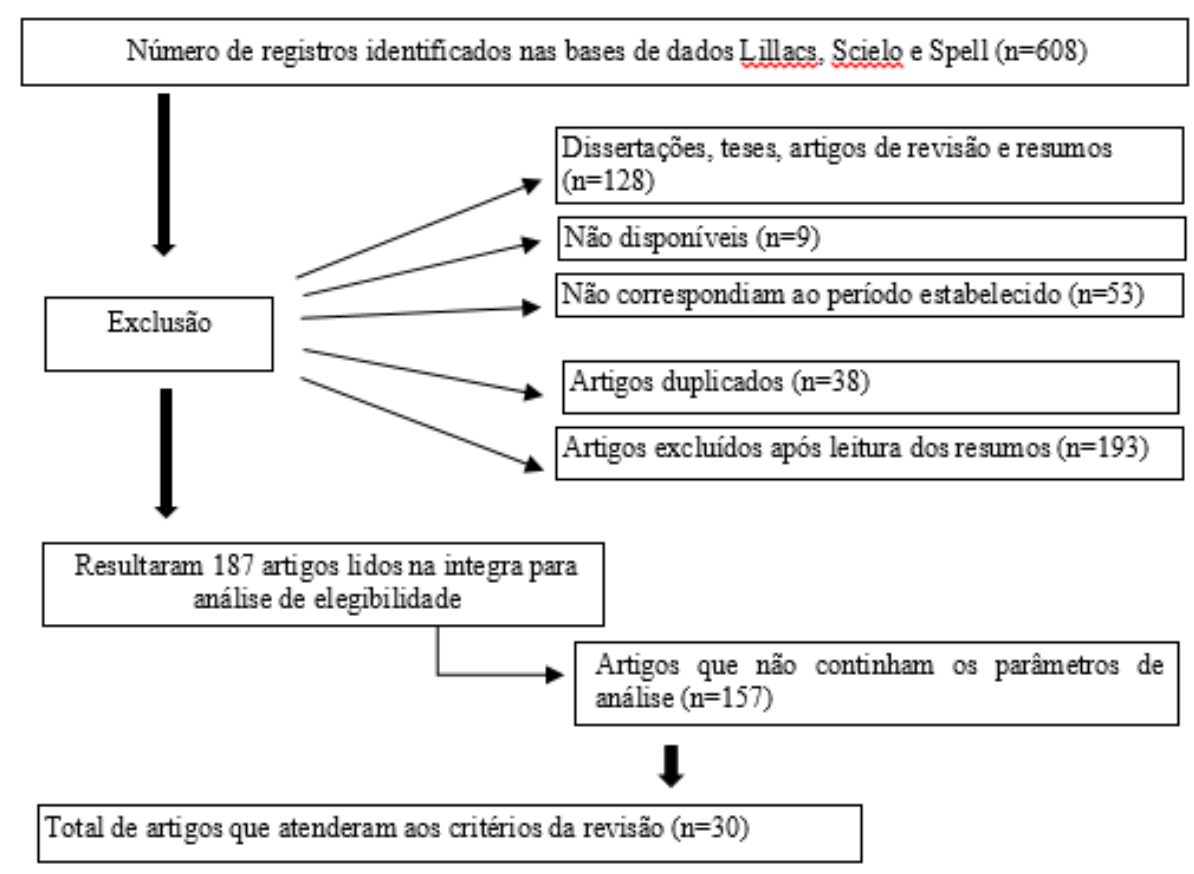

Fonte: Autores.

\section{Resultados}

O Quadro 1 apresenta a caracterização dos artigos em relação ao ano de publicação, autor, procedimentos de coleta, sujeitos da pesquisa e objetivos. Notou-se que, no conjunto dos artigos selecionados, houve publicação de sete artigos antes de 2016 e, posteriormente a este ano, o número total foi de 23 artigos, com maior concentração de estudos publicados em 2018 e 2019, ambos com sete (23,3\%). Não foram encontrados artigos publicados em 2011 e 2012.

Com relação aos procedimentos de pesquisa, dos 30 artigos analisados, percebeu-se que 66,6\% (n=20) utilizaram análise documental, 43,3\% (n=13) realizaram entrevistas semiestruturadas, 23,3\% (n=7) aplicaram questionários, 3,3\% ( $\mathrm{n}=1)$ relatou a realização de observação local e 3,3\% (n=1) entrevista focalizada (Quadro 1).

Em relação aos sujeitos que compuseram as amostras dos estudos, 56,6\% $(n=17)$ privilegiaram a participação de representantes de segmentos administrativos (gestores do PNAE e da agricultura, secretários, diretores e coordenadores de escolas), 46,6\% contaram com nutricionistas $(n=14), 30 \%$ com agricultores familiares $(n=9)$, 16,6\% com membros do Conselho de Alimentação Escolar (CAE) (n=5) e 30\% de outros funcionários (Assistência técnica, manipuladores de alimentos, engenheiros) (n=9). Ressalta-se que 11 artigos $(36,6 \%)$ utilizaram exclusivamente a análise de documentos como fonte de informações (Quadro 1). 
Quadro 1 - Aspectos metodológicos dos artigos científicos sobre a aquisição dos gêneros alimentícios provenientes da agricultura familiar pelo Programa Nacional de Alimentação Escolar - Brasil, 2010-2019.

\begin{tabular}{|c|c|c|c|c|}
\hline Ano & Autor & $\begin{array}{c}\text { Procedimentos de } \\
\text { pesquisa }\end{array}$ & Amostra & Objetivo \\
\hline 2010 & $\begin{array}{l}\text { Triches; } \\
\text { Schneider. }\end{array}$ & $\begin{array}{l}\text { Análise documental } \\
\text { Entrevistas } \\
\text { semiestruturadas. }\end{array}$ & \begin{tabular}{|lr} 
Documentos oficiais $\mathrm{I}, \mathrm{II}$ \\
13 agricultores familiares e & 5 \\
mediadores $\mathrm{I} ; 7$ pais de alunos; 8 \\
diretores; 9 merendeiras; 11 \\
gestores; & 4 \\
gestores/consumidores &
\end{tabular} & $\begin{array}{l}\text { Abordar a relação entre consumo, produção } \\
\text { e políticas públicas alimentares a partir do } \\
\text { Programa de Alimentação Escolar (PAE) } \\
\text { brasileiro, buscando entender como ocorre a } \\
\text { consolidação de sistemas diferenciados de } \\
\text { produção e consumo de alimentos. }\end{array}$ \\
\hline \multirow{3}{*}{2013} & Saraiva et al. & Análise documental. & $\begin{array}{l}\text { 5.317 Demonstrativo Sintético } \\
\text { Anual (DAS) do FNDE. }\end{array}$ & $\begin{array}{l}\text { Apresentar um panorama da compra de } \\
\text { alimentos provenientes da AF, analisando o } \\
\text { seu cumprimento frente às novas diretrizes } \\
\text { de execução do PNAE. }\end{array}$ \\
\hline & Toyoyoshi et al. & Análise documental. & $\begin{array}{l}\text { Formulários de inscrição }{ }^{\mathrm{II}} \text {. } \\
\text { Relatórios de visita técnica }{ }^{\mathrm{II}} \text {. }\end{array}$ & $\begin{array}{l}\text { Avaliar a aquisição de gêneros alimentícios, } \\
\text { advindos da AF pelos municípios } \\
\text { contemplados com o Prêmio Gestor } \\
\text { Eficiente da Merenda Escolar } 2011 .\end{array}$ \\
\hline & $\begin{array}{c}\text { Oliveira; Souza; } \\
\text { Silva }\end{array}$ & $\begin{array}{l}\text { Análise documental. } \\
\text { Entrevista focalizada. }\end{array}$ & \begin{tabular}{|l|l|} 
Notas fiscais $^{\mathrm{II}}$ \\
Pedidos de compras ${ }^{\mathrm{II}}$. \\
Contratos $^{2}$ e relatórios de \\
execuçãoI $^{\mathrm{II}}$. \\
4 Nutricionistas e 2 gestores ${ }^{\mathrm{I}}$. \\
\end{tabular} & $\begin{array}{l}\text { Avaliar a adesão das prefeituras de } \\
\text { Contagem e Betim à Lei nº } 11.947 .\end{array}$ \\
\hline 2014 & $\begin{array}{c}\text { Souza-Esquerdo; } \\
\text { Bergamasco. }\end{array}$ & $\begin{array}{c}\text { Entrevistas } \\
\text { semiestruturadas. }\end{array}$ & $\begin{array}{l}\text { Engenheiros } \\
\text { Nutricionistas }{ }^{\mathrm{II}} \text {. }\end{array}$ & $\begin{array}{l}\text { Analisar a AF nos municípios do chamado } \\
\text { "Circuito das Frutas" do estado de São } \\
\text { Paulo em relação à importância ao acesso } \\
\text { aos principais programas de políticas } \\
\text { públicas que visam o fortalecimento desta } \\
\text { agricultura. }\end{array}$ \\
\hline \multirow[t]{2}{*}{2015} & Gonçalves et. al. & $\begin{array}{c}\text { Questionário } \\
\text { semiestruturado. }\end{array}$ & Nutricionistas ${ }^{\mathrm{II}}$. & $\begin{array}{l}\text { Caracterizar o processo de compra de } \\
\text { alimentos da AF para o PNAE e comparar a } \\
\text { qualidade dos menus servidos aos escolares } \\
\text { antes e após a implementação da Lei } \\
n^{\circ} 11.947 / 09 .\end{array}$ \\
\hline & $\begin{array}{l}\text { Vidal; Veiros; } \\
\quad \text { Souza }\end{array}$ & Análise documental. & 133 cardápios. & $\begin{array}{l}\text { Avaliar a adequação do } \begin{array}{ll}\text { planejamento de } \\
\text { cardápios } \quad \text { escolares } & \text { perante } \\
\text { regulamentação do PNAE. }\end{array} \\
\end{array}$ \\
\hline \multirow{4}{*}{2016} & Alexandre et al. & $\begin{array}{c}\text { Entrevistas } \\
\text { semiestruturadas. }\end{array}$ & 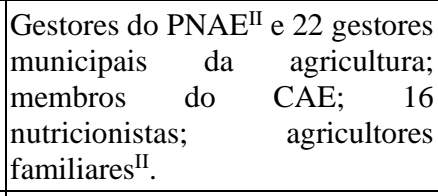 & $\begin{array}{l}\text { Relatar os resultados decorrentes da atuação } \\
\text { da equipe do CECANE UFG na promoção } \\
\text { da compra da AF pelo PNAE em } \\
\text { municípios que compõem dois territórios da } \\
\text { cidadania em Goiás. }\end{array}$ \\
\hline & $\begin{array}{l}\text { Triches; } \\
\text { Barbosa; } \\
\text { Sivestrei }\end{array}$ & Análise documental. & $\begin{array}{l}\text { Chamadas Públicas }{ }^{2} ; \\
\text { dados de prestação de contas }{ }^{I I} \text {. }\end{array}$ & $\begin{array}{l}\text { Examinar a adequação das chamadas } \\
\text { públicas à AF (eficiência) e se o montante } \\
\text { solicitado atendia à legislação. }\end{array}$ \\
\hline & Sodré; Salamoni & $\begin{array}{c}\text { Entrevistas } \\
\text { semiestruturadas. }\end{array}$ & $\begin{array}{l}17 \text { atores: fornecedores de } 3 \\
\text { cooperativas de agricultores } \\
\text { familiares, técnicos das políticas } \\
\text { públicas, entidades executoras. }\end{array}$ & $\begin{array}{l}\text { Abordar as limitações territoriais } \\
\text { enfrentadas pelo PAA e pelo PNAE, em seu } \\
\text { processo de operacionalização no município } \\
\text { de Pelotas/RS. }\end{array}$ \\
\hline & $\begin{array}{c}\text { Oliveira; } \\
\text { Batalha; Pettan }\end{array}$ & $\begin{array}{l}\text { Aplicação de } \\
\text { questionário. }\end{array}$ & $\begin{array}{l}28 \text { agricultores familiares. } \\
\text { Gestores dos } 3 \text { programas }{ }^{\mathrm{II}} \text {. }\end{array}$ & 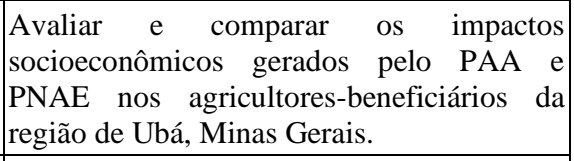 \\
\hline \multirow[t]{2}{*}{2017} & Baccarin et al. & Análise documental. & $\begin{array}{l}\text { Chamadas Públicas II; Contratos } \\
\text { de fornecimento e prestações de } \\
\text { contas das prefeituras }^{\text {II. }}\end{array}$ & $\begin{array}{l}\text { Propor uma sistematização de diversas } \\
\text { variáveis que contribuam para a avaliação } \\
\text { das compras da AF para a alimentação } \\
\text { escolar, apresentando resultados para o } \\
\text { Paraná, Santa Catarina e São Paulo. }\end{array}$ \\
\hline & Gregolin et al. & $\begin{array}{l}\text { Análise documental. } \\
\text { Entrevista } \\
\text { semiestruturadas. }\end{array}$ & \begin{tabular}{|l|} 
Dados secundários do FNDE'; \\
40 entrevistados: Nutricionistas \\
Secretárias de educação \\
de $\quad$ assistência técnicas $^{\text {II }}$
\end{tabular} & $\begin{array}{l}\text { Sistematizar os aspectos referentes à } \\
\text { operacionalização do PNAE no Território } \\
\text { Cantuquiriguaçu, mapeando a sua execução, } \\
\text { quantificando o seu potencial econômico, a }\end{array}$ \\
\hline
\end{tabular}




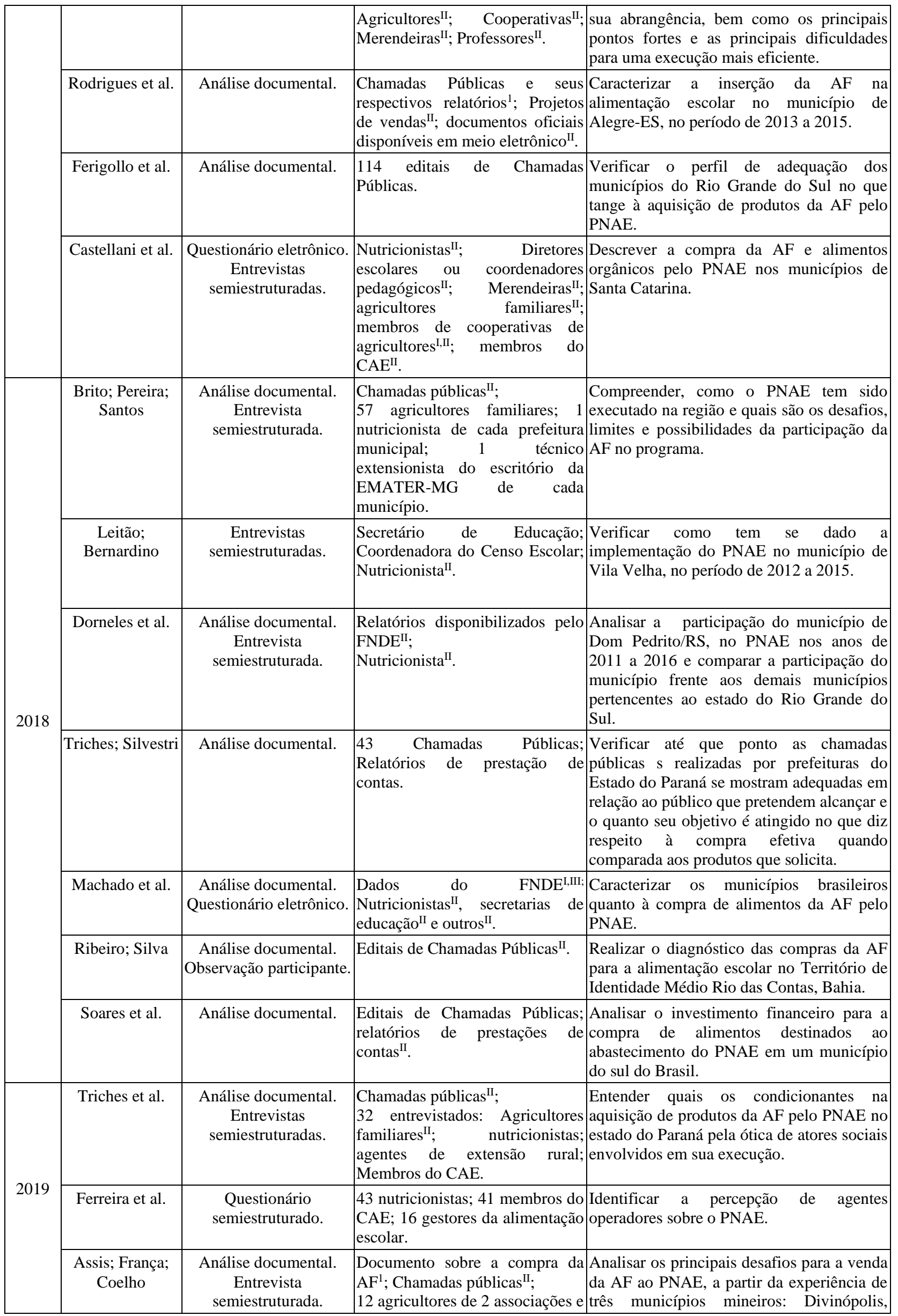




\begin{tabular}{|c|c|c|c|}
\hline & & 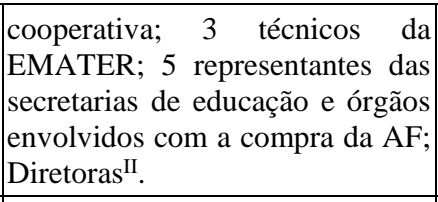 & Guapé e Lavras. \\
\hline $\begin{array}{c}\text { Andrade; } \\
\text { Araújo; Santos }\end{array}$ & Análise documental. & $\begin{array}{l}\text { Documentos do } \\
\text { licitatório }^{\text {II }} \text {. }\end{array}$ & $\begin{array}{l}\text { Verificar como os recursos do FNDE no } \\
\text { âmbito do PNAE para aquisição de gêneros } \\
\text { alimentícios da AF estão sendo aplicados } \\
\text { pelos municípios paraibanos selecionados. }\end{array}$ \\
\hline Souza; Villar & $\begin{array}{l}\text { Questionário } \\
\text { estruturado. }\end{array}$ & $\begin{array}{l}\text { Diretores das escolas; } \\
\text { merendeiros }{ }^{\mathrm{II}} \text {. }\end{array}$ & $\begin{array}{l}\text { Descrever e analisar os aspectos da } \\
\text { implementação da compra da AF, de acordo } \\
\text { com o tipo de gestão do PNAE e } \\
\text { características dos municípios do estado de } \\
\text { São Paulo. }\end{array}$ \\
\hline Rockett et al. & $\begin{array}{l}\text { Questionário on-line } \\
\text { (Survey Monkey). }\end{array}$ & 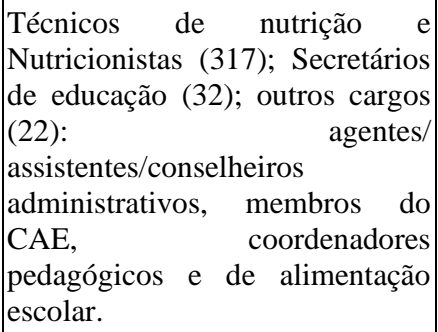 & $\begin{array}{l}\text { Analisar o perfil das compras de produtos } \\
\text { da AF para merenda escolar em municípios } \\
\text { do Rio Grande do Sul (RS), sul do Brasil, } \\
\text { em 2014. }\end{array}$ \\
\hline $\begin{array}{l}\text { Schabarum; } \\
\text { Triches }\end{array}$ & Análise documental. & Notas fiscais e relatórios. & $\begin{array}{l}\text { Verificar como as aquisições públicas de } \\
\text { produtos da AF para o PNAE no estado do } \\
\text { Paraná ocorreram em } 2014 \text { (dados mais } \\
\text { recentes disponibilizados pelo FNDE). }\end{array}$ \\
\hline
\end{tabular}

Notas:

I o estudo não especifica o tipo de documento.

II o estudo não menciona o quantitativo.

AF - Agricultura familiar

PNAE - Programa Nacional de Alimentação Escolar

CECANE - Centro Colaborador em Alimentação e Nutrição Escolar

UFG: Universidade Federal de Goiás

PAA- Programa de Aquisição de Alimentos

CAE - Conselho de Alimentação Escolar

FNDE - Fundo Nacional do Desenvolvimento da Educação

CONAB - Companhia Nacional de Abastecimento

CONSEA - Conselho Nacional de Segurança Alimentar e Nutricional

EMATER/MG - Empresa de Assistência Técnica e Extensão Rural de Minas Gerais

ATER - Assistência Técnica e Extensão Rural

Fonte: Autores.

Considerando a distribuição espacial e abrangência territorial dos estudos, observou-se que dos 30 artigos analisados, 10\% apresentaram abrangência nacional ( $\mathrm{n}=3$ ), incidindo os estudos de Saraiva et al. (2013), Machado et al. (2018) e Toyoyoshi, Oliveira, Santos, Galisa e Galante (2013). Os três trabalhos abrangeram as cinco regiões do país.

Regionalmente, 13 ( $\mathrm{n}=43,3 \%)$ estudos foram realizados na região Sul, sendo seis $(46,1 \%)$ no Paraná, cinco $(38,4 \%)$ no Rio Grande do Sul e dois (15,3\%) em Santa Catarina. Na região Sudeste incidiram nove artigos (30\%), destes, quatro $(44,4 \%)$ foram realizados em Minas Gerais, dois (22,2\%) em São Paulo, dois (22,2\%) no Espírito Santo e um (11,1\%) no Rio de Janeiro. Na região Nordeste analisou-se dois estudos (6,6\%), um da Bahia e o outro da Paraíba. No Centro Oeste brasileiro detectou-se somente um artigo (3,3\%) com análise de municípios no estado de Goiás. Ressalta-se que não foram encontrados artigos de abrangência estadual ou municipal da região Norte do Brasil que analisaram a inserção da AF no PNAE.

Ainda, do total de artigos, dois (6,6\%) descreveram sobre a aquisição da AF para o PNAE considerando somente uma parcela dos estados pertencentes a determinada região de abrangência. Primeiro, o estudo de Gonçalves et al. (2015) que analisou a AF de 82 municípios situados nos estados de São Paulo e Rio de Janeiro. Segundo, o estudo de Baccarin et al. (2017) que abrangeu 353 municípios distribuídos nos estados de Paraná, Santa Catarina (ambos do sul) e São Paulo (sudeste). 
A Tabela 1 mostra os resultados da aplicação dos recursos dos PNAE inferior a 30\% na compra de gêneros alimentícios da AF durante o período de 2009 a 2019. Levando em consideração os estudos apresentados e o número de municípios analisados, observou-se que a maior prevalência do baixo percentual de aquisição ocorreu em municípios da região Sul, sobretudo no ano de 2011 ( $\mathrm{n=597)} \mathrm{e} 2014$ (n=493), seguidos da região Sudeste, também em 2011 (n=522) e 2014 (n=347), Centro-Oeste e Nordeste (Tabela 1).

Tabela 1 - Aplicação menor que 30\% dos recursos do Programa Nacional de Alimentação Escolar na aquisição de gêneros alimentícios provenientes da agricultura familiar, de estados e municípios por região, no período de 2009 a 2019 , Brasil.

\begin{tabular}{|c|c|c|c|c|c|c|c|c|c|c|c|c|c|}
\hline REGIÃO & AUTOR & $\begin{array}{c}\mathrm{N}^{\circ} \text { TOTAL } \\
\text { MUNICÍPIOS } \\
\text { ANALISADOS }\end{array}$ & 2009 & 2010 & 2011 & 2012 & 2013 & 2014 & 2015 & 2016 & 2017 & 2018 & 2019 \\
\hline \multirow[t]{2}{*}{ Centro-oeste } & Alexandre et al & 25 & - & - & - & 13 & 8 & - & - & - & - & - & - \\
\hline & Total & 25 & - & - & - & 13 & 8 & - & - & - & - & - & - \\
\hline \multirow[t]{3}{*}{ Nordeste } & Ribeiro; Silva & $16^{\mathrm{I}}$ & - & - & - & - & - & - & 4 & 4 & 9 & - & - \\
\hline & Andrade; Araújo; Santos & $17^{\mathrm{I}}$ & - & - & 2 & 4 & 11 & 12 & 10 & - & - & - & - \\
\hline & Total & 33 & - & - & 2 & 4 & 11 & 12 & 14 & 4 & 9 & - & - \\
\hline \multirow[t]{10}{*}{ Sudeste } & $\begin{array}{l}\text { Souza-Esquerdo; } \\
\text { Bergamasco }\end{array}$ & $10 I$ & - & - & 3 & 3 & - & - & - & - & - & - & - \\
\hline & $\begin{array}{l}\text { Oliveira; Batalha; } \\
\text { Pettan }\end{array}$ & 1 & - & - & - & 1 & - & - & - & - & - & - & - \\
\hline & Rodrigues et al. & 1 & - & - & - & - & - & 1 & - & - & - & - & - \\
\hline & Brito; Pereira; Santos & 3 & - & - & 1 & & 2 & 2 & 2 & 1 & - & - & - \\
\hline & Leitão; Bernardino & 1 & - & - & - & - & - & - & 1 & - & - & - & - \\
\hline & Ferreira et al. & $38^{\mathrm{I}}$ & - & - & - & - & - & - & 21 & - & - & - & - \\
\hline & Assis; França; Coelho & 3 & - & - & - & - & 2 & 2 & 2 & - & - & - & - \\
\hline & Souza; Villar & $25^{\mathrm{I}}$ & - & - & - & 12 & - & - & - & - & - & - & - \\
\hline & Baccarin et al. & $625^{\mathrm{V}}+637^{\mathrm{VI}}$ & - & - & 113 & - & - & 293 & - & - & - & - & - \\
\hline & Total & 1.344 & - & - & 117 & 16 & 4 & 298 & 26 & 1 & - & - & - \\
\hline \multirow[t]{15}{*}{ Sul } & $\begin{array}{l}\text { Triches;; } \\
\text { Schneider }\end{array}$ & $2^{\mathrm{I}}$ & 1 & - & - & - & - & - & - & - & - & - & - \\
\hline & Gonçalves et al. & $82^{\mathrm{I}, \mathrm{II}}$. & - & - & - & - & 18 & - & - & - & - & - & - \\
\hline & Vidal; Veiros; Souza & 49 & - & 40 & - & - & - & - & - & - & - & - & - \\
\hline & Triches; Barbosa; Sivestrei ${ }^{2}$ & 26 & - & - & - & - & 14 & - & - & - & - & - & - \\
\hline & Sodré; Salamoni & 1 & - & - & - & - & - & 1 & - & - & - & - & - \\
\hline & Gregolin et al. & 20 & - & 3 & 7 & 8 & 7 & 8 & - & - & - & - & - \\
\hline & Ferigollo et al. & 52 & - & - & - & - & 37 & - & - & - & - & - & - \\
\hline & Castellani et al. & 293 & - & - & 207 & - & - & - & - & - & - & - & - \\
\hline & Dorneles et al. & $496^{\mathrm{I}, \mathrm{III}}$ & - & - & 297 & 334 & 272 & 349 & 354 & 331 & - & - & - \\
\hline & Triches; Silvestri & 26 & - & - & - & - & 18 & - & - & - & - & - & - \\
\hline & Triches et al. & 8 & - & - & 4 & 2 & 5 & 3 & 5 & & - & - & - \\
\hline & Rockett et al. & $357^{\mathrm{IV}}$ & - & - & - & - & - & 310 & - & - & - & - & - \\
\hline & Schabarum; Triches & 132 & - & - & - & - & - & 64 & - & - & - & - & - \\
\hline & Baccarin et al. & $688^{\mathrm{V}} 693^{\mathrm{VI}}$ & - & - & 385 & - & - & 460 & - & - & - & - & - \\
\hline & Total & 2.805 & 1 & 43 & 900 & 344 & 371 & 1.196 & 359 & 331 & - & - & - \\
\hline \multicolumn{2}{|c|}{ Total geral por ano } & 4.207 & 1 & 43 & 1.019 & 377 & 394 & 1506 & 403 & 340 & 9 & - & - \\
\hline
\end{tabular}

Notas:

${ }^{\mathbf{I}} \mathrm{O}$ autor não especificou o percentual de algum(ns) município(s).

II 63 municípios de São Paulo e 19 do Rio de Janeiro.

III estudo comparativo de 1 município mais um conjunto (496) de municípios do Rio Grande do Sul, considerou-se apenas o conjunto.

${ }^{\mathrm{IV}}$ número de municípios respondentes sobre a compra de alimentos da $\mathrm{AF}$. 
${ }^{v}$ quantidade de municípios referente a 2011.

${ }^{\text {IV }}$ quantidade de municípios referente a 2014.

Fonte: Autores.

Dos artigos apresentados na Tabela 1, o menor percentual de aplicação dos recursos foi demonstrado no estudo de Souza-Esquerdo e Bergamasco (2014) realizados em 2010, com a utilização de 2,36\% dos recursos por um município de São Paulo (Região Sudeste).

Enfatiza-se também o estudo realizado por Triches, Simonetti, Cessarino, Baccarin e Teo (2019), o qual evidenciou o não cumprimento do percentual exigido por dois municípios de grande porte no Paraná entre os anos de 2011 a 2015 . Já o estudo realizado por Brito, Pereira e Santos (2018), identificou um município de Minas Gerais que não aplicou os recursos do PNAE na AF entre 2012 e 2015.

A Tabela 2 mostra os resultados dos artigos que apresentaram percentual maior que $30 \%$ de aplicação dos recursos do PNAE na aquisição de gêneros alimentícios da AF. Observou-se que a prevalência deste percentual predominou em municípios da região Sul, principalmente em $2011(n=900), 2013(n=371)$ e $2014(n=1.196)$. O Sudeste foi a segunda região com maior número de municípios ( $\mathrm{n}=298$ ) com cumprimento do percentual exigido também em 2014, seguidos da região Nordeste (n=14) em 2015 e Centro-Oeste ( $n=13)$ em 2012.

Entre os artigos descritos na Tabela 2, aponta-se o estudo de Baccarin, Triches, Teo e Silva (2017) que identificou em 2014, o aumento no número de municípios das regiões Sul e Sudeste atendentes ao percentual de aquisição exigido em comparação ao ano 2011. Dorneles et al. (2019) também demonstraram esse aumento nos municípios da região Sul em 2014 e 2015 com redução em 2016 (Tabela 2).

É importante destacar que houve utilização do critério de menor preço por meio de licitação pública para a aquisição de alimentos da AF em 19 municípios de Rio Grande do Sul (região Sul) dos 310 que aplicaram igual ou maior que 30\% dos recursos (Rockett et al., 2019). Outros estudos também evidenciaram esse critério em editais de chamada pública em municípios baianos (região Nordeste) (Dorneles et al., 2019) e mineiros (região Sudeste) (Assis, França, Coelho, 2019). 
Tabela 2 - Aplicação igual ou maior que 30\% dos recursos do Programa Nacional de Alimentação Escolar na aquisição de gêneros alimentícios da agricultura familiar, de estados e municípios por região, no período de 2009 a 2019 , Brasil.

\begin{tabular}{|c|c|c|c|c|c|c|c|c|c|c|c|c|c|}
\hline REGIÃO & AUTOR & $\begin{array}{c}\mathrm{N}^{\circ} \text { TOTAL } \\
\text { MUNICÍPIOS } \\
\text { ANALISADOS }\end{array}$ & 2009 & 2010 & 2011 & 2012 & 2013 & 2014 & 2015 & 2016 & 2017 & 2018 & 2019 \\
\hline \multirow[t]{2}{*}{ Centro-oeste } & Alexandre et al & 25 & - & - & - & 13 & 8 & - & - & - & - & - & - \\
\hline & Total & 25 & - & - & - & 13 & 8 & - & - & - & - & - & - \\
\hline \multirow[t]{3}{*}{ Nordeste } & Ribeiro; Silva & $16^{\mathrm{I}}$ & - & - & - & - & - & - & 4 & 4 & 9 & - & - \\
\hline & Andrade; Araújo; Santos & $17^{\mathrm{I}}$ & - & - & 2 & 4 & 11 & 12 & 10 & - & - & - & - \\
\hline & Total & 33 & - & - & 2 & 4 & 11 & 12 & 14 & 4 & 9 & - & - \\
\hline \multirow[t]{10}{*}{ Sudeste } & $\begin{array}{l}\text { Souza-Esquerdo; } \\
\text { Bergamasco }\end{array}$ & $10 \mathrm{I}$ & - & - & 3 & 3 & - & - & - & - & - & - & - \\
\hline & $\begin{array}{l}\text { Oliveira; Batalha; } \\
\text { Pettan }\end{array}$ & 1 & - & - & - & 1 & - & - & - & - & - & - & - \\
\hline & Rodrigues et al. & 1 & - & - & - & - & - & 1 & - & - & - & - & - \\
\hline & Brito; Pereira; Santos & 3 & - & - & 1 & & 2 & 2 & 2 & 1 & - & - & - \\
\hline & Leitão; Bernardino & 1 & - & - & - & - & - & - & 1 & - & - & - & - \\
\hline & Ferreira et al. & $38^{\mathrm{I}}$ & - & - & - & - & - & - & 21 & - & - & - & - \\
\hline & Assis; França; Coelho & 3 & - & - & - & - & 2 & 2 & 2 & - & - & - & - \\
\hline & Souza; Villar & $25^{\mathrm{I}}$ & - & - & - & 12 & - & - & - & - & - & - & - \\
\hline & Baccarin et al. & $625^{\mathrm{V}}+637^{\mathrm{VI}}$ & - & - & 113 & - & - & 293 & - & - & - & - & - \\
\hline & Total & 1.344 & - & - & 117 & 16 & 4 & 298 & 26 & 1 & - & - & - \\
\hline \multirow[t]{15}{*}{ Sul } & $\begin{array}{l}\text { Triches;; } \\
\text { Schneider }\end{array}$ & $2^{I}$ & 1 & - & - & - & - & - & - & - & - & - & - \\
\hline & Gonçalves et al. & $82^{\mathrm{I}, \mathrm{II}}$. & - & - & - & - & 18 & - & - & - & - & - & - \\
\hline & Vidal; Veiros; Souza & 49 & - & 40 & - & - & - & - & - & - & - & - & - \\
\hline & Triches; Barbosa; Sivestrei & 26 & - & - & - & - & 14 & - & - & - & - & - & - \\
\hline & Sodré; Salamoni & 1 & - & - & - & - & - & 1 & - & - & - & - & - \\
\hline & Gregolin et al. & 20 & - & 3 & 7 & 8 & 7 & 8 & - & - & - & - & - \\
\hline & Ferigollo et al. & 52 & - & - & - & - & 37 & - & - & - & - & - & - \\
\hline & Castellani et al. & 293 & - & - & 207 & - & - & - & - & - & - & - & - \\
\hline & Dorneles et al. & $496^{\mathrm{I}, \mathrm{III}}$ & - & - & 297 & 334 & 272 & 349 & 354 & 331 & - & - & - \\
\hline & Triches; Silvestri & 26 & - & - & - & - & 18 & - & - & - & - & - & - \\
\hline & Triches et al. & 8 & - & - & 4 & 2 & 5 & 3 & 5 & & - & - & - \\
\hline & Rockett et al. & $357^{\mathrm{IV}}$ & - & - & - & - & - & 310 & - & - & - & - & - \\
\hline & Schabarum; Triches & 132 & - & - & - & - & - & 64 & - & - & - & - & - \\
\hline & Baccarin et al. & $688^{\mathrm{V}} 693^{\mathrm{VI}}$ & - & - & 385 & - & - & 460 & - & - & - & - & - \\
\hline & Total & 2.805 & 1 & 43 & 900 & 344 & 371 & 1.196 & 359 & 331 & - & - & - \\
\hline \multicolumn{2}{|c|}{ Total geral por ano } & 4.207 & 1 & 43 & 1.019 & 377 & 394 & 1506 & 403 & 340 & 9 & - & - \\
\hline
\end{tabular}

Notas:

${ }^{1} \mathrm{O}$ autor não especificou o percentual de algum(ns) município(s).

${ }^{2} 63$ municípios de São Paulo e 19 do Rio de Janeiro.

${ }^{3}$ estudo comparativo de um município mais um conjunto (496) de municípios do Rio Grande do Sul, considerou-se apenas o conjunto.

${ }^{4}$ número de municípios respondentes sobre a compra de alimentos da $\mathrm{AF}$.

${ }^{5}$ quantidade de municípios referente a 2011.

${ }^{6}$ quantidade de municípios referente a 2014

Fonte: Autores.

Os resultados dos três artigos (Saraiva et al., 2013; Toyoyoshi et al., 2013; Machado et al., 2018) que analisaram o percentual de aquisição de alimentos da AF para o PNAE com abrangência nacional estão descritos na Tabela 3. Dos estudos apresentados, o de Saraiva et al. (2013) analisou o percentual de municípios que adquiriram da AF por região e demonstrou o maior percentual na região Sul e o menor na região Centro-Oeste. Já o estudo de Machado et al. (2018), por meio de 
Demonstrativos Sintéticos Anuais (DAS), analisou a frequência de municípios por região que adquiriram $\geq 30 \%$ de alimentos da $\mathrm{AF}$ e observou que a maior frequência ocorreu na região Sul e a menor na região Norte (Tabela 3).

Tabela 3 - Estudos nacionais que descreveram sobre a aquisição de gêneros alimentícios da agricultura familiar para o Programa Nacional de Alimentação Escolar, no período de 2009-2019, Brasil.

\begin{tabular}{|c|c|c|c|c|c|c|}
\hline \multirow[t]{3}{*}{ Autor } & \multirow[t]{3}{*}{$\mathrm{N}^{0}$ total de municípios } & \multirow[t]{3}{*}{ Ano } & \multicolumn{4}{|c|}{ Resultados } \\
\hline & & & \multicolumn{4}{|c|}{ Percentual de municípios que adquiriram da AF por Região } \\
\hline & & & $\begin{array}{c}\text { Centro- } \\
\text { oeste }\end{array}$ & Norte & Sudeste & Sul \\
\hline \multirow[t]{3}{*}{ Saraiva et al } & 4.069 & 2010 & $35,3 \%$ & $47,3 \%$ & $42,4 \%$ & $71,3 \%$ \\
\hline & & & \multicolumn{4}{|c|}{ Frequência de municípios que adquiriram $\geq 30 \%$ por região } \\
\hline & & & $\begin{array}{l}\text { Centro- } \\
\text { oeste }\end{array}$ & Norte & Sudeste & Sul \\
\hline \multirow[t]{3}{*}{ Machado et al } & 3.817 & 2011 & $31,6 \%$ & $26,4 \%$ & $41,2 \%$ & $67 \%$ \\
\hline & & & \multicolumn{4}{|c|}{$\mathrm{N}^{\circ}$ de municípios que adquiriram alimentos da $\mathrm{AF}$} \\
\hline & & & $<30 \%$ & \multicolumn{3}{|c|}{$\geq 30 \%$} \\
\hline Toyoyoshi et al & $18^{1}$ & 2011 & 10 & & 8 & \\
\hline
\end{tabular}

Nota: ${ }^{1}$ número de municípios respondentes sobre o percentual de compra de alimentos da AF. Fonte: Autores.

Quanto ao estudo de Toyoyoshi et al. (2013), que analisou dados de municípios selecionados da $8^{\mathrm{a}}$ edição do prêmio gestor eficiente da merenda escolar distribuídos no território nacional, evidenciou a prevalência de municípios que não adquiriram o percentual exigido por lei. Dos que adquiriram igual ou maior que 30\%, houve destaque as cidades de São Lourenço do Sul, no Rio Grande do Sul (51,5\%) (região Sul) e Alto Horizonte, em Goiás (49,2\%) (região Centro-Oeste). Ressalta-se que neste estudo os autores não descreveram a localização regional dos demais municípios.

Destaca-se que inicialmente era o propósito do presente estudo proceder uma correlação do percentual de aplicação dos recursos do PNAE na aquisição de gêneros alimentícios da AF com a modalidade de gestão do PNAE. Não obstante, somente oito $(26,6 \%)$ dentre os 30 artigos totais analisados, fizeram referência a modalidade de gestão (centralizado, descentralizado, semidescentralizado, misto ou terceirizado) (Brito, Pereira \& Santos, 2018; Dorneles et al., 2019; Leitão \& Bernadino, 2018; Machado et al., 2018; Rodrigues et al., 2017; Rockett et al, 2019; Sodré \& Salamoni, 2016; Souza \& Vilar, 2019) e $22(73,3 \%)$ não mencionaram essa informação, inviabilizando a análise.

\section{Discussão}

A obrigatoriedade de aquisição de gêneros alimentícios da AF levou o PNAE a ser reconhecido mundialmente como uma política de SAN estratégica para a garantia do DHAA, sustentabilidade e o desenvolvimento local (Gomes et al., 2018). Nesta perspectiva, inicialmente, chamou a atenção o número relativamente baixo de publicações encontradas sobre o cumprimento do percentual de aplicação dos recursos destinados à aquisição dos gêneros alimentícios pelas secretarias estaduais e municipais de educação.

Entretanto, observou-se uma evolução progressiva de publicações a partir de 2016. Anteriormente a este ano, o total de publicações referentes ao parâmetro de análise da presente revisão foi de sete artigos e a partir de 2016 o número total foi de 23.

Estudos desta natureza são necessários para o diagnóstico da adequação da aplicação dos recursos na AF, assim como, para a compreensão das estratégias e desafios enfrentados pelos governos locais, servindo de subsídios para o monitoramento e redirecionamento do processo de gestão do PNAE (Gregolin, 2016).

Percebeu-se que o baixo número de publicações predominou sobre a região Centro-Oeste, Nordeste e Norte. Nesta última, inclusive, não foram encontradas publicações de abrangência estadual ou municipal. Essa situação pode estar 
relacionada à distribuição desigual de recursos para as instituições de pesquisa, pois nem todas as universidades públicas apesar da integralidade das instituições de ensino superior deverem pautar sua atuação pela indissociabilidade entre o ensino, a pesquisa e a extensão - dispõem de recursos públicos para o desenvolvimento de pesquisas (Ribeiro, 2016).

Em um estudo sobre o financiamento de pesquisas entre 2011 e 2014, Ribeiro (2016) constatou que, dos 24.450 projetos aprovados para financiamento pelo Conselho Nacional de Desenvolvimento Científico e Tecnológico (CNPq), 43,9\% eram da região Sudeste, $23,2 \%$ da região Sul, 19,1\% do Nordeste, 9,2\% do Centro-Oeste e 4,6\% da região Norte. Esses dados demonstram que as regiões Sudeste e Sul obtiveram em todos os anos pesquisados o maior número de projetos aprovados, o que pode justificar, entre outros fatores, o maior número de publicação encontrado sobre estas regiões na presente revisão (Ribeiro, 2016).

Quanto ao percentual de aplicação dos recursos do PNAE na aquisição de gêneros alimentícios da AF menor que $30 \%$, a prevalência ocorreu na região Sul nos anos imediatamente posteriores a imposição determinada pela Lei $\mathrm{n}^{\circ}$ 11.947/2009, conforme ilustra Baccarin et al. (2017) em dois estados da região.

No Sudeste também houve destaque do percentual menor que 30\%, sobretudo no estado de São Paulo em 2011 e 2014 (Baccarin et al., 2017). Muitos municípios nada adquiriram da AF nos anos supracitados, tendo a falta de documentação dos agricultores, principalmente a Declaração de Aptidão ao Pronaf (DAP) como uma das justificativas (Baccarin et al., 2017).

Destaca-se que desde 2009, foi determinada a obrigatoriedade da aplicação de, no mínimo, 30\% dos recursos do PNAE destinados à aquisição de gêneros alimentícios da AF. Durante o período de julho a dezembro de 2009, por se tratar do ano de sua publicação, foi concedido um período de tolerância para que as Entidades Executoras se ajustassem às condições operacionais para a aquisição da AF (Lei no 11.947, 2009).

Entretanto, os estudos evidenciaram que alguns municípios nada aplicaram dos recursos adquiridos do PNAE na AF no período de quatro (2012-2015) (Brito et al., 2018) e cinco anos (2011-2015) (Triches et al., 2019). Algumas razões apontadas para essa inadequação foram à falta de interesse do setor público municipal em fortalecer a articulação entre AF e Alimentação Escolar, a não identificação de agricultores no município e a falta de conhecimento destes sobre o PNAE (Brito et al., 2018; Triches et al., 2019; Vidal, Veiros \& Souza, 2015). Esses problemas identificados poderão ser solucionados através da ampliação de espaços de discussão, agora instituídos na Resolução/CD/FNDE nº 6/2020, por meio da realização de audiências públicas previamente às chamadas públicas.

Em relação ao percentual igual ou maior que $30 \%$ de aplicação dos recursos do PNAE na aquisição da AF, destacaram-se os resultados da região Sul, sobretudo em 2011, 2013 e 2014. Conforme a Figura 2, a qual apresenta o número de estabelecimentos agropecuários por região do Brasil segundo o censo agropecuário de 2017, apesar de não ser a primeira região com maior número de estabelecimentos agropecuários da AF no país (Instituto Brasileiro de Geografia e Estatística [IBGE], 2017), a região Sul é a que possui a maior produção total de alimentos provenientes da AF voltado ao abastecimento interno dos alimentos (Machado et al., 2018; Saraiva et al., 2013), o que pode justificar a intensificação de estudos na região, assim como, o percentual de recursos aplicados na compra de alimentos da AF para o PNAE estabelecido em Lei.

Em relação à região Sudeste, a expressiva quantidade de municípios que cumpriram o percentual exigido é compatível com o último censo agropecuário realizado no país, que indicou ser esta a segunda região com maior número de estabelecimentos agropecuários (IBGE, 2017), com forte presença da AF (Figura 2). Assim, pressupõe-se que há a capacidade de fornecimento regular e constante dos gêneros alimentícios por parte dos agricultores familiares, explicando devida aplicação de recursos em percentual igual ou maior que $30 \%$ por parte dos estados e municípios (Mossmann, Teo Busato \& Triches, 2017).

A aparente contradição da região Sul e Sudeste oscilar entre aquelas que aplica os percentuais de recursos menores que $30 \%$ e igual ou maior que $30 \%$, pode ser decorrente de três fatores: primeiro, os estudos variam em relação ao período: em 
anos imediatamente posteriores à publicação da Lei, os municípios estavam em fase de reorganização dos processos para adequação à Lei; segundo, o local de vigência: alguns municípios distribuídos nestes estados apresentam determinantes que podem favorecer ou dificultar a aquisição dos gêneros alimentícios; terceiro, o número de pesquisas que incidiram sobre estas regiões é maior, repercutindo mais a situação das mesmas.

Figura 2 - Números de estabelecimentos agropecuários por região do Brasil segundo o censo agropecuário de 2017 - Brasil, 2017.

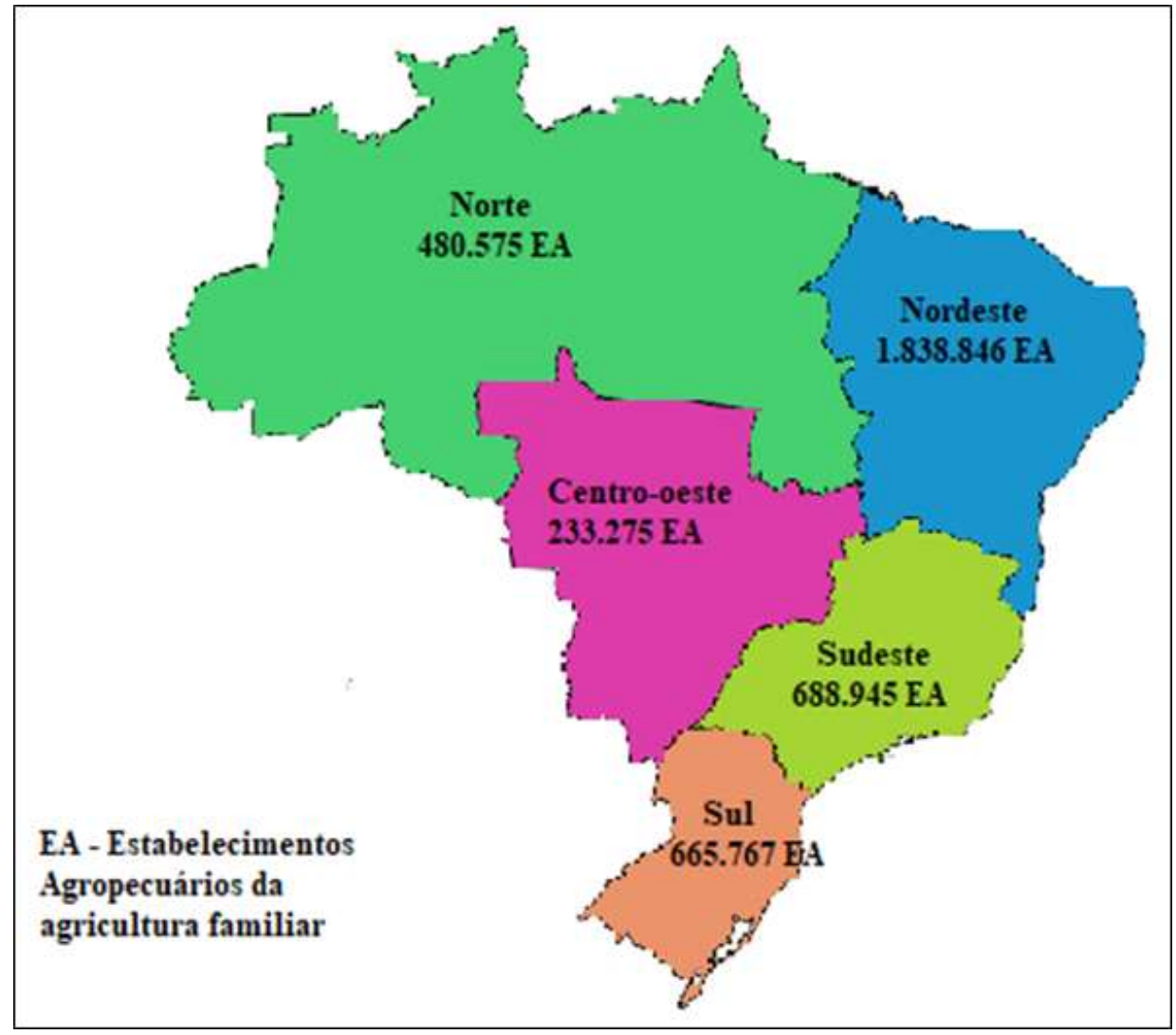

Fonte: Instituto Brasileiro de Geografia e Estatística (IBGE), 2017.

Em relação ao Nordeste, embora seja a região cujo número de estabelecimentos agropecuários é o maior do país (IBGE, 2017) (Figura 2), a maior parte da região está situada na zona semiárida e possui graves problemas socioambientais decorrentes das secas periódicas, o que pode prejudicar a produção de alimentos, demandar maior custo e investimento (Lira, 2016). Ademais, os recursos do governo federal para essa região, por meio dos programas agropecuários, são significativamente menores quando comparados às regiões Sul e Sudeste (Cardoso, Smith, Cordeiro \& Montano, 2015).

Esta situação pode justificar que na região Nordeste, tenha se observado uma baixa prevalência de municípios que compraram alimentos da AF, evidenciado em um estudo de abrangência nacional (Saraiva et al., 2013), assim como, a baixa prevalência de municípios que atingiram o percentual exigido em outro estudo de mesma abrangência (Machado et al., 2018).

É importante discutir que no estudo realizado em municípios da Bahia, foi utilizado o critério de menor preço em editais de chamada pública por alguns municípios (Ribeiro \& Silva, 2018), o que provoca uma disputa entre os preços, fazendo com que os agricultores diminuam os valores dos alimentos para conseguir ganhar a chamada (Brito et al., 2018). Isso dificulta a aquisição de renda necessária para a subsistência das famílias, dado o baixo poder aquisitivo em que geralmente vivem os produtores dessa região (Lira, 2016). 
Em relação ao cumprimento do percentual exigido, destaca-se que não foi possível obter conclusões precisas sobre os recursos aplicados na aquisição da AF na região Nordeste, dado o baixo número encontrado de publicações.

Quanto à região Centro-oeste, segundo os estudos de abrangência nacional, foi a região que apresentou o menor percentual de municípios que compraram da AF (Saraiva et al., 2013), e a segunda região que obteve menor frequência de municípios que adquiriram um percentual $\geq 30 \%$ nos anos de 2011 (Machado et al., 2018) e em 2013, demonstrado, no estudo de Alexandre et al. (2016). Essa evidência pode estar associada ao baixo número de estabelecimentos agropecuários da AF na região (IBGE, 2017) (Figura 2), ao predomínio de produção ligada ao agronegócio e à pouca produção da $\mathrm{AF}$ se comparada à região Sudeste, por exemplo (Saraiva et al., 2013).

A área total da AF na região Centro-oeste é de 9.969.750 hectares e da agricultura não familiar é de 102.034 .572 hectares (IBGE, 2017), o que deixa evidente o predomínio do agronegócio e sinaliza a dificuldade do cumprimento do percentual exigido na legislação do PNAE. No entanto, faz-se necessários maiores estudos para evidenciar o percentual de aplicação dos recursos do PNAE na AF, devido ao baixo número de publicações encontrado.

Quanto à região Norte, um estudo de abrangência nacional demonstrou a participação de quase metade do total de municípios analisados na compra da AF em 2010 (Saraiva et al., 2013). Outro estudo de mesma abrangência revelou um baixo número de municípios que cumpriram o percentual mínimo de aplicação de recursos exigidos por Lei (Machado et al., 2018).

Esses resultados podem estar associados ao fato da região Norte ter um número inferior de estabelecimentos rurais da AF (IBGE, 2017), quando comparada com as regiões Nordeste, Sudeste e Sul (Figura 2). Nesta região também chama a atenção o tamanho da área de produção da agricultura não familiar em detrimento da área de produção familiar, a qual apresenta tamanho duas vezes menor, o que pode dificultar com que os agricultores familiares forneçam seus gêneros de forma regular e permanente ao PNAE (Castellani et al., 2017; Rockett et al., 2019; Saraiva et al., 2013; Sodré \& Salamoni, 2016; Toyoyoshi et al., 2013).

Salienta-se que a região Norte enfrenta inúmeros desafios em relação às atividades agropecuárias, dentre eles a disputa pela posse da terra, a preservação ambiental, o êxodo rural, o financiamento da produção, assim como, o envolvimento de questões políticas, sociais, ambientais, tecnológicas e econômicas (Castro, 2013). Assim, a produção de novas evidências científicas nesta região identificará as dificuldades da participação dos agricultores familiares no PNAE, e possibilitará o planejamento estratégico de ações e programas públicos de garantia de sua inserção no mercado institucional do PNAE.

Enfatiza-se que, devido ao baixo número de evidências encontrado, não foi possível obter conclusões precisas sobre o percentual de aplicação dos recursos utilizados por estados e municípios da região Norte na aquisição de gêneros alimentícios da AF para o PNAE.

Destaca-se que a modalidade de gestão do PNAE dos municípios das cinco regiões do país, não foi relatada pela maioria dos estudos analisados. Trata-se de um aspecto importante a ser considerado na análise da aplicação dos recursos do PNAE e que pode ter forte influência na compra de alimentos da AF. Corroborando esta suposição, dentre os poucos estudos que fizeram menção à modalidade de gestão do PNAE, observou-se que, quando a gestão era centralizada, houve maior percentual de aplicação de recursos na aquisição dos alimentos da AF (Brito et al., 2018; Machado et al., 2018; Souza \& Villar, 2019; Rockett, 2019).

Ressalta-se que a Resolução/CD/FNDE no 26 (2013), previa o desconto dos recursos que não foram gastos com a AF e não foram justificados, no ano subsequente, passando a responsabilidade da oferta da alimentação escolar à Entidade Executora com seus recursos próprios quando da suspensão dos repasses. Ainda, a Resolução limita a reprogramação para o ano subsequente a $30 \%$ dos recursos recebidos, passando estes a serem descontados das próximas parcelas (Resolução/CD/FNDE n ${ }^{\circ}$ 26, 2013). Atualmente, com a Resolução no 6, 2020, ficou instituído que o percentual não aplicado 
deverá ser avaliado no processo de prestação de contas por parte dos municípios, e o valor correspondente deverá ser devolvido no ano seguinte, ou seja, em 2021 (Resolução nº 6, 2020).

Ademais, o FNDE poderá suspender os repasses dos recursos caso haja irregularidades por parte dos municípios e estados na execução do PNAE. Ocorrendo a suspensão, o FNDE poderá efetuar o repasse dos recursos equivalentes diretamente às unidades executoras, correspondentes às escolas atingidas, para fornecimento da alimentação escolar para aquisição emergencial dos gêneros alimentícios (Lei nº 11.947, 2009; Resolução/CD/FNDE n 38, 2009; Resolução nº 6, 2020).

Quanto às limitações do presente estudo, está a escassez de estudos que incluíram a modalidade de gestão do PNAE como variável de análise.

\section{Conclusão}

Os resultados demonstraram que os municípios e estados das cinco regiões do Brasil adquiriram alimentos da AF para o PNAE. Houve uma maior prevalência daqueles que cumpriram o percentual de aplicação dos recursos financeiros exigidos nas regiões Sul e Sudeste, respectivamente. Os dados também demonstraram experiências exitosas em alguns municípios da região Nordeste e Centro-oeste em relação ao cumprimento do percentual mínimo de compra estabelecido na legislação, mas em outros, essa recomendação ainda não foi alcançada.

Os resultados da presente revisão confirmam a hipótese de que os municípios apresentam dificuldades distintas no cumprimento do percentual exigido e estas estão associadas as desigualdades socioeconômicas, culturais e ambientais vivenciadas em cada região.

O não atendimento ao percentual mínima de compras da AF pelo PNAE reflete na perda do potencial oferecido pelo PNAE como política pública de incentivo ao desenvolvimento regional.

As evidências demonstraram a importância da fiscalização da aplicação dos recursos destinados ao PNAE no âmbito municipal em todas as regiões, dado o número de municípios não adequados à Lei nos anos analisados.

Sugere-se que trabalhos futuros investiguem como está o processo de aquisição dos gêneros alimentícios da AF para a alimentação escolar, para ampliar as investigações sobre o cumprimento do percentual mínimo exigido em Lei nas diversas regiões do país e contemplem a modalidade de gestão como variável de análise.

\section{Referências}

Alexandre, V. P., Gomes, L. O. F., Silva, S. U., Almeida, G. M., Martins, K. A., Monego, E. T, Sousa, L. M., \& Campos, M. R. H. (2016). Do campo à escola: compra de alimentos da agricultura familiar pelo Programa Nacional de Alimentação Escolar em Territórios da Cidadania de Goiás. Segur Alim Nutric, 23, 1049-1064.

Andrade, J. C., Araujo, M. A., \& Santos, P. V. S. (2019). Estudo sobre aquisição de alimentos da agricultura familiar para o programa nacional de alimentação escolar. Gestão e Socied, 13(36):3062-3089.

Araujo, L. R. A., Brito, A. N. M., Rodrigues, M. T. P., Mascarenhas, M. D. M., \& Moreira-Araujo, R. S. R. (2019). Alimentação escolar e agricultura familiar: análise de recursos empregados na compra de alimentos. Cad Saúde Pública,35(11): 1-9.

Assis, T. R. P., França, A. G. M., \& Coelho, A. M. (2019). Agricultura familiar e alimentação escolar: desafios para o acesso aos mercados institucionais em três municípios mineiros. Rev de Econ Sociol Rural, 57(4), 577-593.

Baccarin, J. G., Triches, R. M., Teo, C. R. P. A., \& Silva, D. B. P. (2017). Indicadores de Avaliação das Compras da Agricultura Familiar para Alimentação Escolar no Paraná, Santa Catarina e São Paulo. Rev Econ Sociol Rural, 55(1): 103-122.

Brito, T. P., Pereira, V. G., \& Santos, A. P. (2018). Os limites, desafios e Potencialidades da agricultura Familiar no PNAE em municípios Atingidos pela mineração. Retratos de Assentados, 21(2):192-224.

Cardoso, M. P., Smith, G., Cordeiro, J. P. V., \& Montano, P. F. (2015). Apoio à agropecuária sustentável e à inclusão sócioprodutiva na Região Sudeste. In: Leal, C. F. C., Lemos, L. L. C., Silva, M. M., Lastres, H. M. M. (org), Um olhar territorial para o desenvolvimento: Sudeste (p.206-231). Rio de Janeiro, RJ: Banco Nacional de Desenvolvimento Econômico e Social. 
Castellani, A. L. A., Trentini, T., Nishida, W., Rossi, C. E., Costa, L. C. F., \& Vasconcelos, F. A. G. (2017). Purchase of family farm and organic foods by the Brazilian School Food Program in Santa Catarina state, Brazil. Rev Nutri, 30(5):651-662.

Castro, C. N. (2013). A agropecuária na região norte: oportunidades e limitações ao desenvolvimento. Instituto de Pesquisa Econômica Aplicada, Brasília: Rio de Janeiro: Autor.

Dorneles, F. M., Mainardi, C. F., Bettencourt, A. F., Pires, R. G., Simões, F. S. B., \& Nascimento, S. G. S. N. (2019). Panorama da aquisição de alimentos da Agricultura Familiar para o Programa Nacional de Alimentação Escolar em um município do Rio Grande do Sul. ECoDAF, 4(1):86-101.

Ferigollo, D., Kirsten, V. R., Heckler, D., Figueredo, O. A. T., Perez-Cassarino, J., \& Triches, R. M. (2017). Aquisição de produtos da agricultura familiar para alimentação escolar em municípios do Rio Grande do Sul. Rev Saúde Pública, 51(6): 01-10.

Ferreira, D. M., Barbosa, D. M. F., Finizola, N. C., Soares, D. S. B., Henriques, P., Pereira, S., Carvalhosa, C. S., Siqueira, A. B. F. S., \& Dias, P. C. (2019). Percepção de agentes operadores do Programa Nacional de Alimentação Escolar. Rev Saúde Pública, 53(34):1-13.

Gomes, A. C., Depontil, C. M., Arend, S. C., Etges, V. E., Karnopp, E, Silva, T. L., \& Boer, A. I. (2018). O mercado institucional da compra de alimentos da Agricultura familiar - PAA E PNAE - no território do vale do Rio pardo/RS. Desenv Reg em debate, 8(1): 4-24.

Gonçalves, H. V. B., Cunha, D. T., Stedefeldt, E., \& Rosso, V. V. (2015). Family farming products on menus in school feeding: a partnership for promoting healthy eating. Ciência Rural, 45(12): 2267-2273.

Gregolin, G. A. (2016). O estado da arte da avaliação de políticas públicas: conceituação e exemplos de avaliação no Brasil (Dissertação de Messtrado). Universidade Estadual do Oeste do Paraná, Paraná, Brasil.

Gregolin, M. R. P, Santos, C. S., Felippini, M. L., Mateus, M. A. F., \& Christoffo, P. I. (2017). Potencialidades e Fragilidades do Programa Nacional de Alimentação Escolar - PNAE no Território Cantuquiriguaçu (PR). Conexao UEPG, 13(3):548-567.

Instituto Brasileiro de Geografia e Estatística. (2017). Censo Agropecuário de 2017. Brasil: Autor.

Lei $n^{\circ} 11.947$, de 16 de junho de 2009. (2009). Dispõe sobre o atendimento da alimentação escolar e do Programa Dinheiro Direto na Escola aos alunos da educação básica. Brasília, DF. Disponível em: http://www.planalto.gov.br/ccivil_03/_Ato2007-2010/2009/Lei/L11947.htm.

Leitão, A. L. E., \& Bernardino, R. V. B. (2018). Programa Nacional de Alimentação Escolar (PNAE): experiência de aquisição de produtos de agricultores familiares para alimentação escolar em Vila Velha- ES. Geografares, 284-309.

Lira, J. S. (2016). Resiliência da Agricultura Familiar no Nordeste Brasileiro (Dissertação de Mestrado). Universidade Federal do Ceará, Fortaleza, Brasil.

Machado, P. M. O., Schmitz, B. A. S., Gonzalez-China, D. A., Corso, A. C. T., Vasconcelos, F. A. G., \& Gabriel, C. G. (2018). Compra de alimentos da agricultura familiar pelo Programa Nacional de Alimentação Escolar (PNAE): estudo transversal com o universo de municípios brasileiros. Ciênc. saúde coletiva, 23(12): 4153-4164.

Malaguti, J. M. A. (2015). Programa Nacional de Alimentação Escolar (PNAE): desafios para a inclusão dos produtos da agricultura familiar na merenda escolar de Itapecerica da Serra - SP (Dissertação de mestrado). Universidade Federal do Estado de São Paulo, Osasco (SP), Brasil.

Messias, S. L. (2018). A chamada pública como alternativa à licitação: seu uso na quisição de produtos da agricultura familiar para a alimentação escolar (Dissertação de Mestrado). Faculdade de Ciências Humanas e Sociais, Franca (SP), Brasil.

Mossmann, M. P., Teo, C. R. P. A., Busato, M. A., \& Triches, R. M. (2017). Interface between family farming and school feeding: barriers and coping mechanisms from the perspective of different social actors in Southern Brazil. Rev Econ Soc Rural, 55(2): $325-342$.

Oliveira, L. G., Batalha, M. O., \& Pettan, K. B. (2017). Comparative assessment of the food purchase program and the national school feeding program's impact in Ubá, Minas Gerais, Brazil. Ciência Rural, 47(1):1-6.

Oliveira, T. R. P. R., Sousa, H. C., \& Silva, A. P. (2013). Agricultura familiar na alimentação escolar. Nutrire: Rev Soc Bras Alim Nutr, 38(3):256-268.

Pedraza, D. F, Melo, N. L. S, Silva, F. A, A\& raújo, E. M. N. (2018). Avaliação do Programa Nacional de Alimentação Escolar: revisão da literatura. Cienc Saúde Colet., 23(5):1551-1560.

Peixinho, A. M. L. (2013). A trajetória do Programa Nacional de Alimentação Escolar no período de 2003-2010: relato do gestor nacional. Cien Saude Colet., 18(4): 909- 916

Pereira, A. S., Shitsuka, D. M., Parreira, F. J. \& Shitsuka, R. (2018). Metodologia da pesquisa científica. Universidade Federal de Santa Maria. https://repositorio.ufsm.br/bitstream/handle/1/15824/Lic_Computacao_Metodologia-Pesquisa-Cientifica.pdf?sequence=1 .

Resolução n. ${ }^{\circ}$ 4, de 3 de abril de 2015. (2015). Altera a redação dos artigos 25 a 32 da Resolução/CD/FNDE n. ${ }^{\circ} 26$, de 17 de junho de 2013 , no âmbito do Programa Nacional de Alimentação Escolar (PNAE). Brasília, DF. http://www.gestaoescolar.diaadia.pr.g ov.br/arquivos/File/alimenatacao_escolar/resolucao042015_ceae.pdf.

Resolução $n^{o}$ 6, de 8 de maio de 2020. (2020). Dispõe sobre o atendimento da alimentação escolar aos alunos da educação básica no âmbito do Programa Nacional de Alimentação Escolar - PNAE. Brasília, DF. https://www.in.gov.br/en/web/dou/-/resolucao-n-6-de-8-de-maio-de-2020-256309972.

Resolução/CD/FNDE $n^{\circ}$ 26, de 17 de junho de 2013. (2013). Dispõe sobre o atendimento da alimentação escolar aos alunos da educação básica no âmbito do Programa Nacional de Alimentação Escolar - PNAE. Brasília, DF. https://www.fnde.gov.br/index.php/acesso-a-informacao/institucional/legislaca o/item/4620-resolu\%C3\%A7\%C3\%A3o-cd-fnde-n\%C2\%BA-26,-de-17-de-junho-de-2013. 
Resolução/CD/FNDE $n^{o} 38$, de 16 de julho de 2009. (2009). Dispõe sobre o atendimento da alimentação escolar aos alunos da educação básica no Programa Nacional de Alimentação Escolar (PNAE). Brasília, DF. 2009. https://www.fnde.gov.br/index.php/acesso-a-informacao/institucional/legislacao/item/3341resolu\% $3 \%$ A7\% $3 \%$ A3o-cd-fnde-n\%C2\%BA-38-de-16-de-julho-de-2009.

Ribeiro, D. B. (2016). As universidades brasileiras e a indução estratégica da pesquisa: o comprometimento da autonomia científica (Tese de Doutorado). Universidade Federal do Espírito Santo, Vitória (ES), Brasil.

Ribeiro, J. S., \& Silva, W. S. (2018). Compras da Agricultura Familiar para atender ao PNAE no território rural médio Rio das Contas - BA (2015-2017). $R E C o D A F, 4(2): 2018$.

Rockett, F. C., Corrêa, R. S., Pires, G. C., Machado, L. S., Hoerlle, F. S., Souza, C. O. M., \& Oliveira, A. B. A. (2019). Family farming and school meals in Rio Grande do Sul, Brazil. Ciência Rural, 49(2):1-12.

Rodrigues, R., Siqueira, H. M., Biancardi, C. C. S., Andrade, M. A. N., Valente, L. M. V., \& Paula, L. B. (2017). A aquisição de alimentos da agricultura familiar pelo PNAE no município de Alegre-ES. Demetra, 12(1); 91-112.

Saraiva, E. B., Silva, A. P. F., Sousa, A. A., Cerqueira, G. F., Chagas, C. M. S., \& Toral, N. (2013). Panorama da compra de alimentos da agricultura familiar para o Programa Nacional de Alimentação Escolar. Ciênc Saúde Colet., 18(4):927-935.

Schabarum, J. C., \& Triches R. M. (2019). Aquisição de Produtos da Agricultura Familiar em Municípios Paranaenses: análise dos produtos comercializados e dos preços praticados. Rev Econ Soc Rural, 57(01): 049-062.

Silva, A. P. F., \& Souza, A. A. (2013). Alimentos orgânicos da agricultura familiar no Programa Nacional de alimentação Escolar do Estado de Santa Catarina, Brasil. Rev Nutr, 26(6):701-714.

Soares, P., Martinelli, S. S., Fabri, R. K., Veiros, M. B., Davó-Blanes, M. C., \& Cavalli, S. B. (2018). Programa Nacional de Alimentação Escolar como promotor de Sistemas Alimentares Locais, Saudáveis e Sustentáveis: uma avaliação da execução financeira. Ciênc Saúde Colet, $23(12)$ : $4189-4197$.

Sodré, M. T., \& Salamoni, G. (2016). A coexistência do pensamento cartesiano e sistêmico: As limitações territoriais enfrentadas pelo PAA e PNAE em Pelotas/RS. Socied Nat, 28 (3): 457-471.

Souza, M. G. S., \& VIllar, B. S. (2019). Acquisition of family farm foods in municipalities of São Paulo state: The infl uence of the management of the School Feeding Program and municipal characteristics. Rev Nutr, 32:1-14.

Souza-esquerdo, V. F., \& Bergamasco, S. M. P. P. (2014). Análise sobre o acesso aos programas de políticas públicas da agricultura familiar nos municípios do Circuito das Frutas (SP). Rev Econ Soc Rural, 52(1): 205-222.

Toyoyoshi, J. Y., Oliveira, R., Santos, M. S. N., Galisa, M. S., \& Galante, A. P. (2013). Avaliação da aquisição de gêneros alimentícios provenientes da agricultura familiar para a alimentação escolar. O Mundo da Saúde 2013; 37(3): 329-335.

Triches, R. M., \& Schneider, S. (2010). Alimentação escolar e agricultura familiar: reconectando o consumo à produção. Saúde Soc., 19(4):933-45.

Triches, R. M., Barbosa, L. P, \& Silvestri F. (2016). Agricultura Familiar e Alimentação Escolar no Estado do Paraná: uma análise das chamadas públicas. Rev paranaense de desenvolvimento, 37(130): 29-43.

Triches, R. M., \& Silvestri, F. (2018). Adequação das Chamadas Públicas para Aquisição de Produtos da Agricultura Familiar para a Alimentação Escolar. Desenvolvimento em Questão, 16(44), 233-259.

Triches, R. M., Simonetti, M. G., Cessarino, J. P., Baccarin, J. G., \& Teo, C. R. P. A. (2019). Condicionantes e limitantes na aquisição de produtos da agricultura familiar pelo Programa de Alimentação Escolar no estado do Paraná. Redes, 24(1): 118-137.

Vidal, G. M., Veiros, M. B, \& Sousa, A. A. (2015). School menus in Santa Catarina: Evaluation with respect to the National School Food Program regulations. Rev Nutric, 28(3): 277-287. 